\title{
Selection of a breast cancer subpopulation-specific antibody using phage display on tissue sections
}

\author{
Simon Asbjørn Larsen ${ }^{1}$. Theresa Meldgaard ${ }^{2}$ Agla J. Fridriksdottir ${ }^{3}$. \\ Simon Lykkemark ${ }^{4,5}$ - Pi Camilla Poulsen ${ }^{2}$ Laura F. Overgaard ${ }^{2}$. \\ Helene Bundgaard Petersen ${ }^{2} \cdot$ Ole William Petersen ${ }^{3} \cdot$ Peter Kristensen $^{2}$
}

Published online: 12 May 2015

(C) The Author(s) 2015. This article is published with open access at Springerlink.com

\begin{abstract}
Breast cancer tumors are composed of heterogeneous cell populations. These populations display a high variance in morphology, growth and metastatic propensity. They respond differently to therapeutic interventions, and some may be more prone to cause recurrence. Studying individual subpopulations of breast cancer may provide crucial knowledge for the development of individualized therapy. However, this process is challenged by the availability of biomarkers able to identify subpopulations specifically. Here, we demonstrate an approach for phage display selection of recombinant antibody fragments on cryostat sections of human breast cancer tissue. This method allows for selection of recombinant antibodies binding to antigens specifically expressed in a small part of the tissue section. In this case, a CD271 ${ }^{+}$subpopulation of breast cancer cells was targeted, and these may be potential breast cancer stem cells. We isolated an antibody fragment
\end{abstract}

Electronic supplementary material The online version of this article (doi:10.1007/s12026-015-8657-x) contains supplementary material, which is available to authorized users.

Peter Kristensen

pk@eng.au.dk

1 Department of Molecular Biology and Genetics, Aarhus University, Aarhus, Denmark

2 Department of Engineering, Aarhus University, Aarhus, Denmark

3 Department of Cellular and Molecular Medicine, Centre for Biological Disease Analysis and Danish Stem Cell Centre, University of Copenhagen, Copenhagen, Denmark

4 Department of Clinical Medicine, Aarhus University, Aarhus, Denmark

5 Sino-Danish Centre for Education and Research (SDC), Aarhus, Denmark
LH 7, which in immunohistochemistry experiments demonstrates specific binding to breast cancer subpopulations. The selection of antibody fragments directly on small defined areas within a larger section of malignant tissue is a novel approach by which it is possible to better target cellular heterogeneity in proteomic studies. The identification of novel biomarkers is relevant for our understanding and intervention in human diseases. The selection of the breast cancer-specific antibody fragment LH 7 may reveal novel subpopulation-specific biomarkers, which has the potential to provide new insight and treatment strategies for breast cancer.

Keywords Phage display - Biomarkers - Breast cancer . Tissue $\cdot \mathrm{CD} 271^{+} \cdot$ Shadow stick

\section{Introduction}

Breast cancer is characterized as being a very heterogeneous disease [1]. Effective detection, diagnosis and treatment are challenged by this heterogeneity. The heterogeneity in breast cancer greatly affects morphology, growth rate, metastatic propensity, therapeutic resistance and recurrence [2]. Breast cancer heterogeneity exists both between tumors as different subtypes (inter-tumor heterogeneity) and within a given tumor (intra-tumor heterogeneity). Multiple molecular subtypes among patients have been identified, each differing with respect to prevalence, prognosis and approach of treatment. The five most commonly used classifications to account for the inter-tumor heterogeneity include the luminal A, luminal B, basal-like, HER 2 and normal-like subtypes [3-6]. These subtypes mainly differ in the expression of the estrogen, progesterone, ErbB2 receptors and certain cytokeratins. Breast cancer is also characterized by intra-tumor 
heterogeneity. Therefore, multiple biopsies taken from the same tumor may reveal profound genomic variations, which indicate the presence or absence of different subpopulations within the tumor [7]. Two proposed models have hypothesized the cause for intra-tumor heterogeneity. According to the theory of clonal evolution, the genetic variations in the cells of a primary tumor are under selective pressure to adapt to their particular microenvironment [8]. These cells accumulate genetic and epigenetic alterations over time, and the selection pressure drives the evolution. The most adaptive cells become responsible for tumor progression and may form increasingly malignant, metastatic or drug-resistant tumors. This concept is supported by studies showing that metastatic potential coincides with genetic instability [9]. Another hypothesis involves cancer stem cells (CSC), which were initially identified in acute myeloid leukemia, but have since been reported in a wide variety of cancers [10]. This particular subpopulation may initiate tumors but also possess the ability to self-renew by either symmetric or asymmetric cell division, and they are capable of forming differentiation hierarchies within the tumor [11]. This differentiation generates heterogeneous cell lineages which constitute the bulk of the tumor and play different roles in metastasis, tumor recurrence and drug resistance. Today, it is becoming increasingly accepted that these two models are not mutually exclusive. Studies on leukemia stem cells have also shown that these particular CSCs may undergo clonal evolution themselves [12]. Hence, different breast cancer subpopulations occurring within the same tumor may be the result of both clonal evolution and CSCs [13]. Another consideration is that intra-tumor heterogeneity is not only shaped by intrinsic factors, but also by the complex network of cellular interactions with the microenvironment in which the tumor resides. Surrounding stroma cells, extracellular matrix, paracrine factors or local conditions such as hypoxia have all been shown to influence tumor progression [14-17]. The microenvironment may also influence therapeutic response [18]. Thus, the unique characteristics of an individual tumor derive from a combination of both intra-tumor heterogeneity and tumor microenvironment.

Here, we utilize phage display technology on cryostat breast cancer tissue to generate recombinant antibody fragments that specifically recognize subpopulations. We apply a method, which allows selections to be targeted at small subpopulations of primary breast cancer cells in tissue [19]. The use of cryostat tissue as biological material allows inclusion of the tumor microenvironment in the selections, which may provide antibody fragments of high clinical relevance. Selection was performed against $\mathrm{CD} 271^{+}$breast cancer cells directly on the tissue. These cells not only have the ability to initiate tumors, but are also capable of forming a differentiation hierarchy [20].
In this study, we demonstrate the selection of the antibody fragment LH 7, which bind an antigen expressed by certain breast cancer subpopulations. The discovery of LH 7 may allow further characterization of breast cancer subpopulations and bring new insights to the breast cancer field.

\section{Materials and methods}

\section{Tissue sections}

Cryostat sections $(6-8 \mu \mathrm{m})$ from snap-frozen biopsies of breast cancer patients and healthy donors were prepared as described [21]. The use of human material has been reviewed by the Regional Scientific Ethical Committees (Region Hovedstaden) and approved with reference to $\mathrm{H}-2$ 2011-052 and H-2-2010-051. Tissue sections used for selections were fixed for $10 \mathrm{~min}$ in $3.7 \%$ formaldehyde (Sigma-Aldrich), washed in PBS and incubated twice for $7 \mathrm{~min}$ in $0.01 \%$ Triton X-100 (Sigma-Aldrich). Nuclei were counterstained with hematoxylin (Sigma-Aldrich). Selections were performed on basal-like breast cancer tissue from patient 757 [22] with the marker profile: $\left(\mathrm{ER} / \mathrm{PR}^{-/-}\right.$, cytokeratin $(\mathrm{CK}) 17^{+}, \mathrm{CK}^{+}$, low ErbB2, $\mathrm{MM}^{+}$ and $\mathrm{CD} 271^{+}$). Tissue sections used for immunohistochemistry (IHC) were fixed in ice-cold methanol (Sigma-Aldrich) at $-20{ }^{\circ} \mathrm{C}$ for $5 \mathrm{~min}$. Tissue sections from four breast cancer patients were used, two basal-like breast cancers: P757 and P918 $\left(\mathrm{ER}^{-}, \mathrm{CK}_{17}{ }^{+}, \mathrm{CK}^{+}, \mathrm{MM}^{-}\right.$and $\left.\mathrm{CD} 271^{+}\right)$and two luminal breast cancers: P761 $\left(\mathrm{ER} / \mathrm{PR}^{+/+}, \mathrm{CK} 17^{-}, \mathrm{CK}^{+}\right.$, low ErbB2, $\mathrm{MM}^{+}$and $\left.\mathrm{CD}_{271^{+}}\right)$and $\mathrm{P} 686\left(\mathrm{ER}^{\mathrm{PR}}{ }^{+/+}\right.$, $\mathrm{CK} 17^{-}, \mathrm{CK}^{-}$, low ErbB2, $\mathrm{MM}^{+}$and $\mathrm{CD} 271^{+}$).

\section{Target area identification by immunoperoxidase staining with anti-CD271}

Briefly, multiple sections were cut. The middle section was methanol-fixed and used for immunoperoxidase, while the other sections were formalin-fixed as described. The tissue from the middle section was encircled with a PAP pen liquid blocker and blocked for $5 \mathrm{~min}$ in Ultra V Block (TA060-UB, Thermo scientific). The tissue was incubated for $1 \mathrm{~h}$ with $50 \mu \mathrm{L}$ mouse anti-p75 NGF receptor antibody (anti-CD271) [ME20.4] 1:50 (abcam, \#ab8877), washed three times with PBS $\left(\mathrm{Ca}^{2+}\right.$ and $\mathrm{Mg}^{2+}$ free) and then incubated with $50 \mu \mathrm{L}$ Ultravision ONE HRP Polymer (Thermo Scientific) for $30 \mathrm{~min}$, washed three times with PBS and finally incubated with $1 \mathrm{mg} / \mathrm{mL} \quad 3^{\prime}, 3^{\prime}$-diaminobenzidine tetrahydrochloride (DakoCytomation) in PBS with freshly added $1 \mu \mathrm{L} / \mathrm{mL}$ of $30 \% \mathrm{H}_{2} \mathrm{O}_{2}$ (SigmaAldrich) for $10 \mathrm{~min}$. The tissue slide was washed with PBS and distilled water before the nuclei were counterstained with hematoxylin (Sigma-Aldrich). CD271 ${ }^{+}$cancer cells 
were found within a cancer nest in the methanol-fixed section. Corresponding areas were identified on the formalin sections and used for shadow stick selection.

\section{Shadow stick}

The shadow sticks were fabricated from pulled injection microcapillaries (Tritech research, USA). The metal disks were made by compressing sinter metal powder, kindly provided by Dansk Sintermetal (Denmark). The flat pieces of powdered metal were placed on a microscope slide and attached to the tip of a pulled glass capillary by drawing up a small volume of epoxy glue into the capillary. Subsequently, the glue was dispensed on top of a piece of metal with a desired size. This procedure was done with the capillary attached to the micromanipulator, to ensure the disk being glued to the stick in the correct angle. This allows positioning of the disk on top of the target area using micromanipulation equipment from Narishige (Model MM188, Nikon, Tokyo, Japan). A shadow stick with a diameter of approximately $150 \mu \mathrm{m}$ was used in this study.

\section{Shadow stick selection of antibody fragments using phage display}

The breast cancer tissue sections from P757 were formalinfixed and blocked $1 \mathrm{~h}$ in $4 \%$ Marvel dried skimmed milk powder (MPBS). The tissue slide was incubated with the phage library in a slide container containing $20 \mathrm{~mL} 2 \%$ MPBS overnight with gentle agitation. The single-domain library "predator" was used which has diversity of $6.2 \times 10^{7}$ different antibody fragments and a titer of $10^{13} \mathrm{pfu} / \mathrm{mL}$ with a display level estimated to be $6.4 \%$ [23]. Fifty microliters phage stock was used per tissue section and incubated overnight. The slide was washed $10 \mathrm{~min}$ in PBS and two times $10 \mathrm{~min}$ in PBS with $10 \%$ glycerol (PBSG) with gentle agitation. The slide was dried except from the target area, which was kept moist with approximately $10 \mu \mathrm{L}$ PBSG. Using brightfield microscopy, the shadow stick was positioned above the target area. The slide was exposed to UV-C light $(254 \mathrm{~nm}$ ) for $5 \mathrm{~min}$ using a UV-C source (model UVSL-14P from UVP, Upland, CA, USA) positioned on a stand approximately $4 \mathrm{~cm}$ above the slide. Phage particles bound to the target area was eluted with $15 \mu \mathrm{L}$ trypsin $(1 \mathrm{mg} / \mathrm{mL})$ for $15 \mathrm{~min}$. Trypsin was aspirated and transferred to a tube before the area was washed 15 times with $50 \mu \mathrm{L}$ PBSG, which was transferred to the eluate as well. For trypsin inactivation, $50 \mu \mathrm{L}$ fetal bovine serum was added to the eluate before storage at $-20{ }^{\circ} \mathrm{C}$.

\section{Cell cultures}

Myoepithelial cells were isolated from trypsinized organoids derived from normal breast tissue as previously described [24]. The trypsinized cells were incubated with fluorescent monoclonal anti-NGFR (neurotrophin receptor, p75)/CD271-APC (ME20.4, 1:50, Cedarlane Laboratories) for $45 \mathrm{~min}$ at $4{ }^{\circ} \mathrm{C}$ and then washed $2 \mathrm{x}$ in HEPES buffer supplemented with $0.5 \%$ BSA (bovine fraction V; SigmaAldrich) and 2 mM EDTA (Merck) and finally incubated with $1 \mu \mathrm{g} / \mathrm{mL}$ propidium iodide (Life Technologies) to separate live from dead cells before analysis and sorting, using a FACSAria I flow cytometer (BD Biosciences). Sorted cells were set up in culture on collagen-coated flasks with BBMYAB medium. Establishment and culture of the $\mathrm{CD}_{271^{+}}$subclone from the BT474 cancer cell line were performed as described [20].

\section{Phage ELISA for screening and titration assay}

Phage infection of E. coli and the production of phage antibodies were performed as described [19]. Initial screening of potential interesting phage antibodies was performed on $\mathrm{CD} 271^{+}$cancer cells. Titration assay was performed simultaneously on both $\mathrm{CD} 271^{+}$cancer cells and normal CD271 ${ }^{+}$myoepithelial cells, which enabled the possibility to reject the phage antibodies binding to common antigens. The assays were performed as described [19]. As a positive control for the phage ELISA procedure, the phage antibody 52 was used [25]. As a negative control, a phage antibody specific against fetal epsilon-hemoglobin was included [26]. For titration assay, phage antibodies of interest were produced in $50 \mathrm{~mL}$ TG-1 cultures and tested along with the above-mentioned controls in series of five fourfold serial dilutions, ranging from $10^{11}$ phages/well to $3.9 \times 10^{8}$ as described [19]. Phage particles were quantified by measuring absorbance at $269 \mathrm{~nm}$ and $320 \mathrm{~nm}$ [23].

\section{Expression and purification of soluble antibody fragments}

To express the individual clones as soluble antibody fragments, they were sub-cloned from the predator phagemid into a modified pET22b vector including c-Myc- and Histag using NcoI and NotI restriction enzymes (Thermo Scientific) and T4 DNA ligase (Fermentas) before transformation into BL21 Gold (Agilent Technologies). Expression was initiated with a $4 \mathrm{~mL}$ overnight culture in TB medium containing ampicillin $(100 \mu \mathrm{g} / \mathrm{mL})$ and glucose $(4 \% \mathrm{w} / \mathrm{v})$. The cultures were diluted 1:100 in $250 \mathrm{~mL}$ cultures and grown until $\mathrm{OD}_{600}$ of $0.6-0.8$ and then spun for $10 \mathrm{~min}$ at $4{ }^{\circ} \mathrm{C}$ and $4000 \mathrm{rpm}$. The pellet was re-suspended into TB medium containing ampicillin $(100 \mu \mathrm{g} / \mathrm{mL})$ and IPTG $(100 \mu \mathrm{g} / \mathrm{mL})$ for induction and grown $16-18 \mathrm{~h}$ at $30^{\circ} \mathrm{C}$ and $200 \mathrm{rpm}$. The cultures were spun for $1 \mathrm{~h}$ at $5000 \mathrm{~g}$ at $4{ }^{\circ} \mathrm{C}$, and the antibody fragments in the supernatant was precipitated with $30 \%$ w/v ammonium sulfate by incubation 
on a roller table at $4{ }^{\circ} \mathrm{C}$ overnight. The flasks were spun for $30 \mathrm{~min}$ at $5000 \mathrm{~g}$ at $4{ }^{\circ} \mathrm{C}$ and the pellet re-suspended in $40 \mathrm{~mL}$ TBS (pH 8) with approximately 400 U DNase I (Roche) including $5 \mathrm{mM} \mathrm{Mg}{ }^{+}$. The solution was sterilefiltered with $0.20 \mu \mathrm{m}$ filters (GF prefilters) and purified on HiTrap Protein A HP columns (GE Healthcare). The fractions containing the antibody fragments were determined by SDS-PAGE, pooled into a $3.5 \mathrm{kDa} \mathrm{MW}$ dialysis tube (Spectrum Laboratories) and dialyzed in $3 \mathrm{~L} \mathrm{TBS} \mathrm{pH} 7.5$ at $4{ }^{\circ} \mathrm{C}$ overnight with gentle agitation. The dialyzed protein was transferred to $3 \mathrm{kDa} \mathrm{MW}$ VivaSpin columns (GE Healthcare) and spun down to a concentration of about $1 \mathrm{mg} / \mathrm{mL}$ measured on a NanoDrop spectrophotometer (Thermo Fisher Scientific). Purity was verified by SDSPAGE and Western blotting against c-Myc.

\section{Immunohistochemical staining with soluble domain antibody fragments}

The tissue sections were prepared as earlier described. The tissue was encircled with a PAP pen and blocked for $1 \mathrm{~h}$ with Ultra V Block (TA-060-UB, Thermo scientific). Approximately $25 \mu \mathrm{g}$ antibody fragments were dissolved in Ultra V Block, $10 \%$ goat serum and 1:100 anti-CK19 to a total volume of $100 \mu \mathrm{L}$ and added to the encircled area. Incubation was performed for $3 \mathrm{~h}$ in humid chambers. The liquid was removed by aspiration, and the slide was washed four times $1 \mathrm{~min}$ in PBS. The slide was incubated for $30 \mathrm{~min}$ in the dark with mouse Cy3-conjugated anti-c-Myc antibody [9E10] 1:250 (Sigma-Aldrich), Alexa Fluor 488-conjugated goat anti-mouse IgG2a 1:500 (Invitrogen), DAPI 1:1000 (Invitrogen) and 10\% goat serum dissolved in Ultra V Block to $100 \mu \mathrm{L}$. Alternatively, the antibody fragments above were replaced with an anti-Ki67 antibody (Abcam) in a dilution of 1:100, and as secondary antibody, a goat anti-rabbit antibody coupled to Alexa 546 (Life technologies) was added in dilution of 1:500. The slide was washed three times $1 \mathrm{~min}$ in PBS and mounted with Fluoromount mounting media (Sigma-Aldrich) and cover glass.

\section{Results}

\section{Outline}

The shadow stick selection procedure on cryostat tissue sections is based on our previous published work [19]. An outline of the selection and screening approach applied in this study can be observed in Fig. 1. The selections were performed with a novel single-domain phage antibody library termed "predator" [23].

\section{Identifying the target area}

Selections were performed on multiple sections from a single biopsy (P757) which had small well-defined tumor cell nests and rare $\mathrm{CD} 271^{+}$staining throughout the tissue. The target area was chosen to be a high-density cluster of $\mathrm{CD} 271^{+}$cells within a single cancer nest (Fig. 1). The shadow stick shielded roughly 75-100 cells. Structural changes to the presentation of antigens might occur in the multiple steps of the CD271 immunostaining. Therefore, the selection was performed on separate, but consecutive non-stained tissue sections in order to preserve the antigens to the best ability. The consecutive slides were formalin-fixed and used fresh, and the target area was kept moist under all steps of the selection procedure. The exact corresponding target area was easily identified on the neighboring slides by the unique morphology patterns of the tumor cell nests.

\section{Selections and screening}

Thirteen selections were performed on cryostat sections from the breast cancer patient 757 using the shadow stick on the target area as described; 315 clones were initially screened by phage ELISA on CD271 expressing cancer cells with phage antibodies produced in 96-well format. The phage antibody "epsilon" is specific against epsilonhemoglobin almost exclusively expressed by fetal erythroblasts [26]. This phage antibody was included as negative control in the initial ELISA screening. Its absorbance value was chosen as a cutoff value to determine which of the 315 clones should be further analyzed. The initial ELISA screen serves the sole purpose of prioritizing clones for further analysis. The screening yielded 35 phage antibodies with higher absorbance compared with the negative control epsilon. The selection outputs of the predator library were generally of good quality, and sequencing of the individual genes encoding these 35 antibodies of interest revealed no stop codons, truncations, frameshift mutations or other abnormalities as expected. The 35 phage antibodies were produced in $50 \mathrm{~mL}$ cultures and tested by titration phage ELISA in series of five fourfold serial dilutions, ranging from $10^{11}$ phages/well to $3.9 \times 10^{8}$ phages/well. This was performed simultaneously on both $\mathrm{CD} 271^{+}$cancer cells and $\mathrm{CD} 271^{+}$myoepithelial cells. This allows for comparison between the individual phage antibodies and the two cell lines. The phage antibodies binding equally well or better to myoepithelial cells were considered as common epitope binders and not tested further. Eleven out of the 35 tested phage antibodies were prioritized for further validation as they bound better to the $\mathrm{CD} 271^{+}$cancer cells compared to the CD271 ${ }^{+}$myoepithelial cells. Soluble antibody fragments were expressed and purified before validation by IHC. 


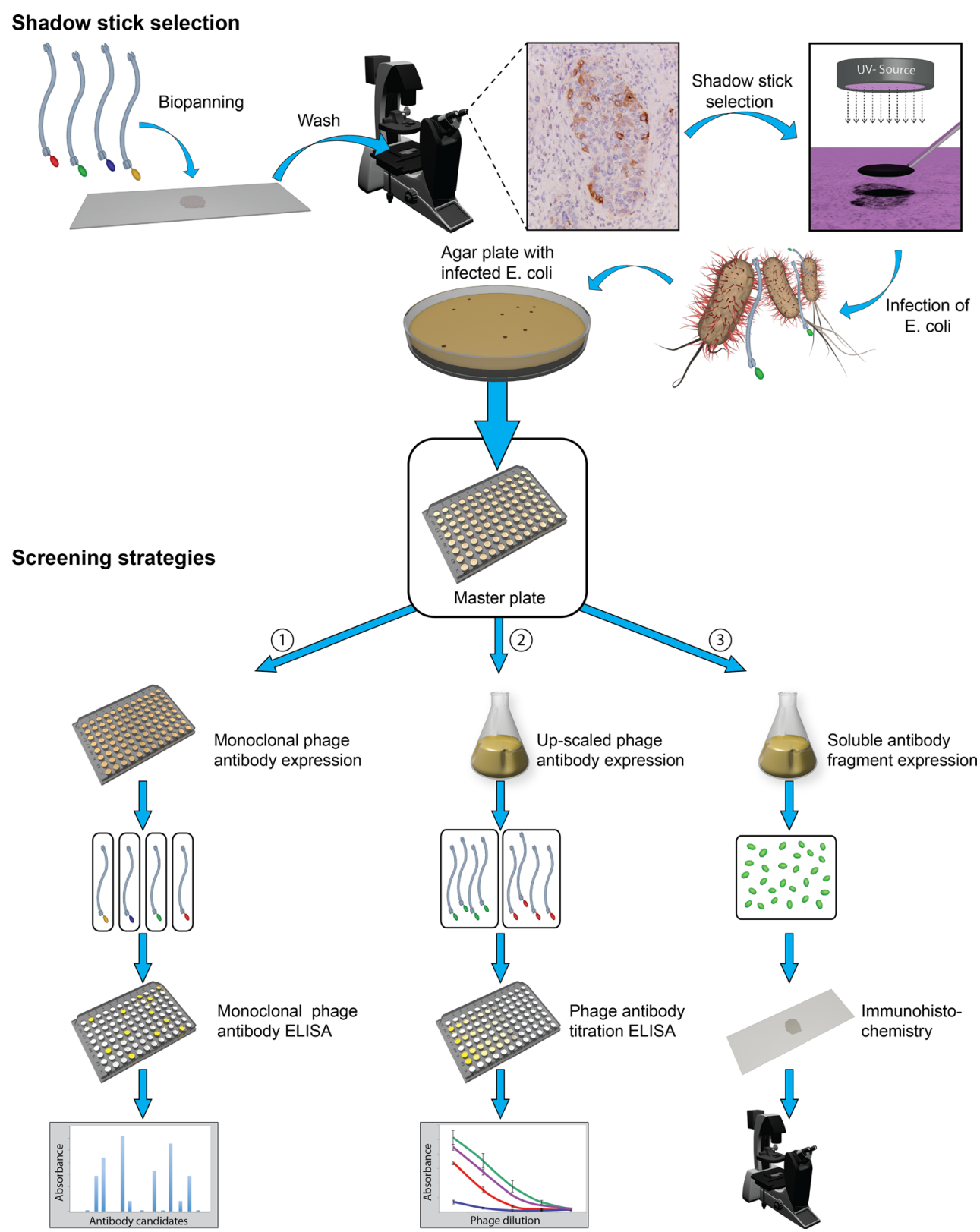

Fig. 1 Illustration of the antibody fragment selection procedure and screening strategies. The target area for selection was chosen to be the middle part of a particular cancer nest due to clustered CD271 staining present here. The entire tissue on a consecutive formalinfixed section was then incubated with a phage library. The target area was relocated, and a minute disk (shadow stick) was positioned precisely above the target cells of interest. The target area was kept moist at all times. The shadow stick shielded the phage antibodies binding to the cells of interest from UV-C irradiation. The phages were eluted, but only those protected by the shadow stick can replicate in bacteria and provide ampicillin resistance. Each colony represented an antibody fragment, which required screening for their specificity. They were picked and grown in separate wells of a master plate. (1) In the initial screening, all colonies were grown in microtiter plates and monoclonal phage antibodies were produced. The phage antibodies were tested by phage ELISA on CD271 ${ }^{+}$cancer cells. (2) All phage antibodies binding with higher affinities than the negative control in the initial screening were produced monoclonally in $50 \mathrm{~mL}$ cultures. These were tested in different concentrations by a phage ELISA titration assay, which was performed simultaneously on $\mathrm{CD} 271^{+}$cancer cells and CD271 ${ }^{+}$myoepithelial cells. This provided comparative results of each phage antibody. (3) Soluble antibody fragments were expressed and purified and examined by IHC experiments on four different breast cancer biopsies to validate their specificity 

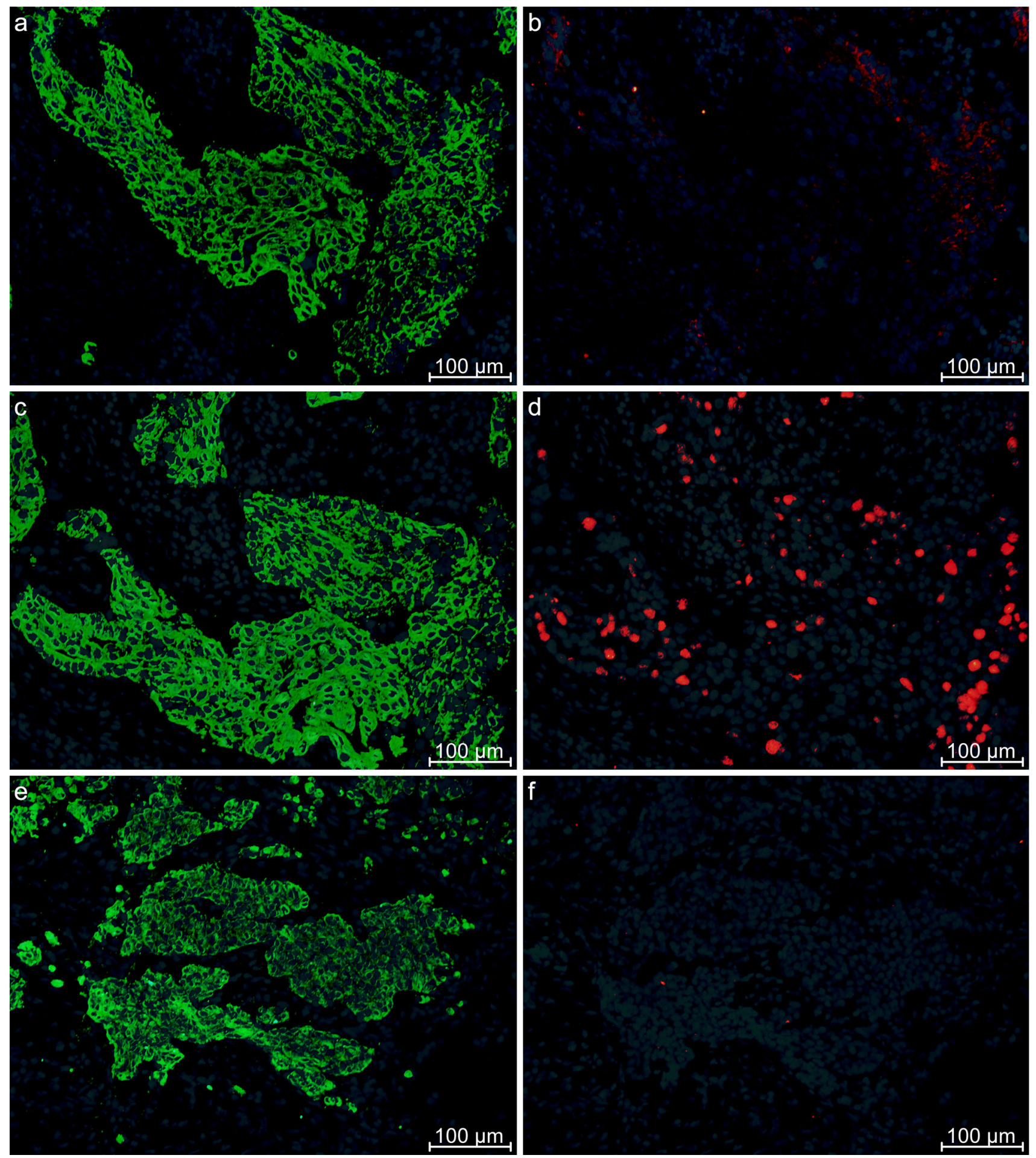

Fig. 2 Immunohistochemistry on three separate sections of cryostat tissue from a basal-like breast cancer of patient 757, the same biopsy as selected upon. All pictures are merged with DAPI staining. The pictures a, c and e show staining against CK19, which indicate the presence of cancer cells. Picture $\mathbf{b}$ shows staining with the antibody fragment LH 7 which consistently only binds to a subset of cancer cells. The presence of cancer cells is confirmed by the staining with

the proliferation marker ki67 within these areas as observed in picture d. Pictures $\mathbf{e}$ and $\mathbf{f}$ are from a different area than picture $\mathbf{a}-\mathbf{d}$, but it is the same biopsy. Picture $\mathbf{f}$ shows staining with the mouse $\mathrm{Cy} 3-$ conjugated anti-c-Myc antibody used for detection of the antibody fragments. This shows that the observed staining is not caused by upregulated c-Myc expression in the cancer cells or unspecific binding by this secondary antibody 

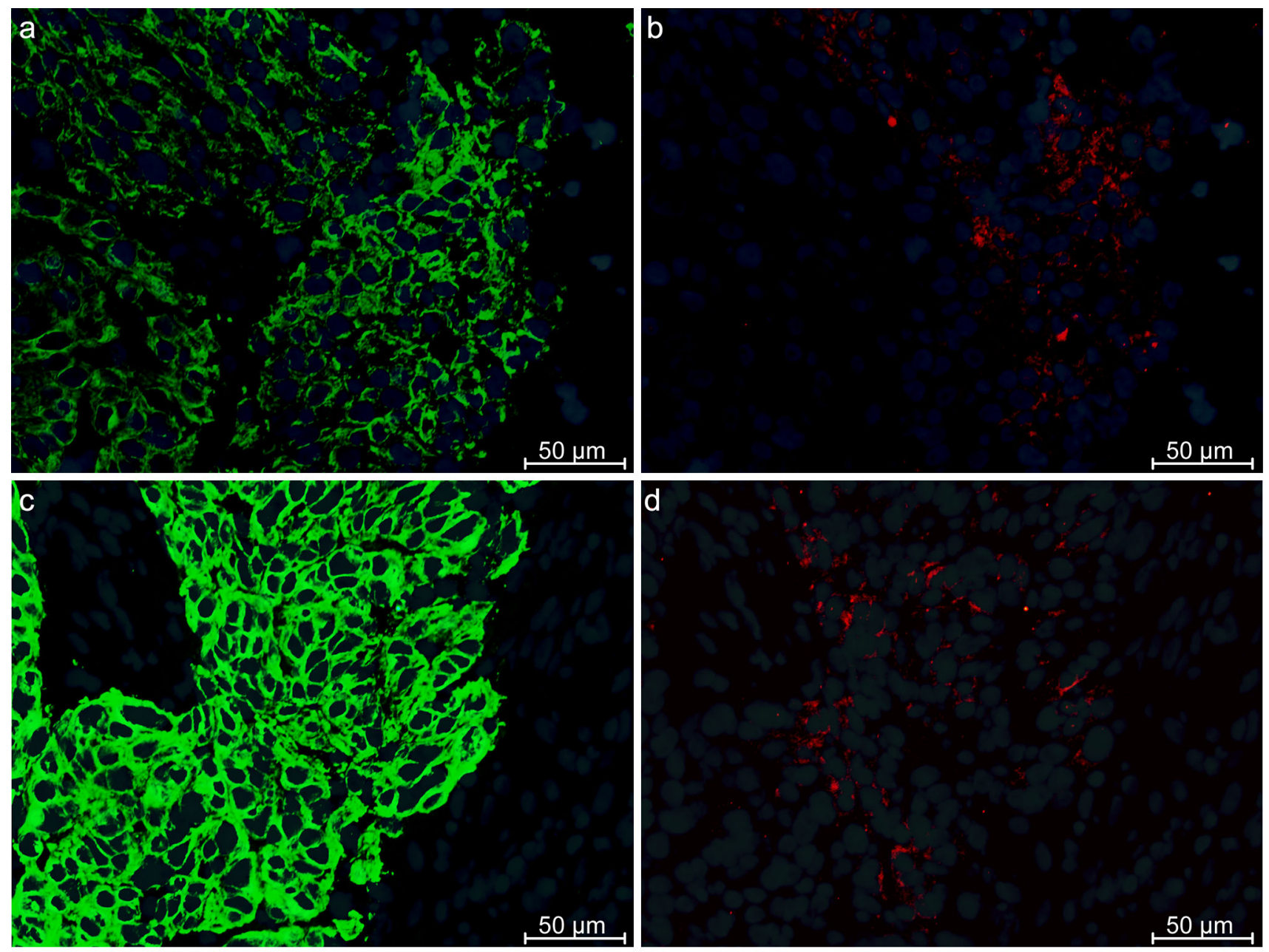

\section{d}
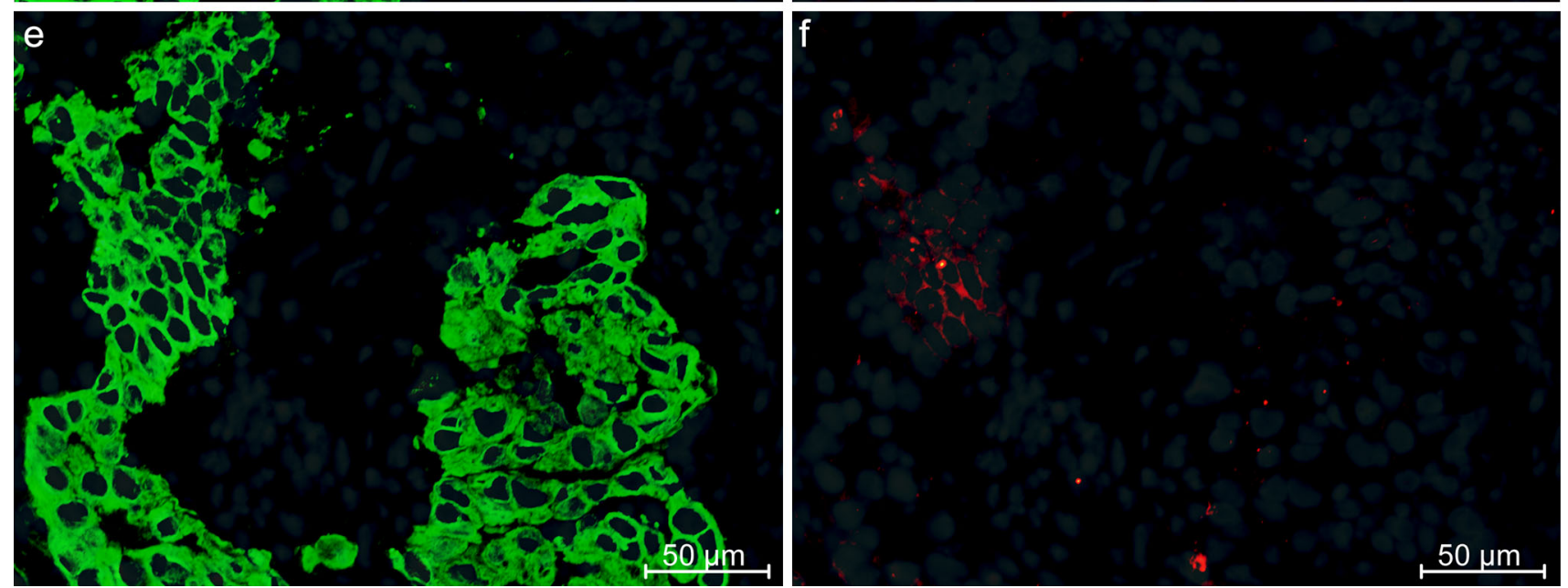

Fig. 3 Immunohistochemistry showing three different areas on the same section of a cryostat tissue from a basal-like breast cancer of patient 757. All pictures are merged with DAPI staining. The pictures a, $\mathbf{c}$ and e show staining against CK19. Picture b shows staining with the antibody fragment LH 7 and is the exact same area as presented in

Fig. 2b, but at higher magnification. Pictures $\mathbf{d}$ and $\mathbf{f}$ are LH 7 staining from other areas. Although all the pictures are from the same biopsy, there are slight variations in the staining pattern. Picture $\mathbf{f}$ shows more condensed or grouped staining compared with the other two areas 

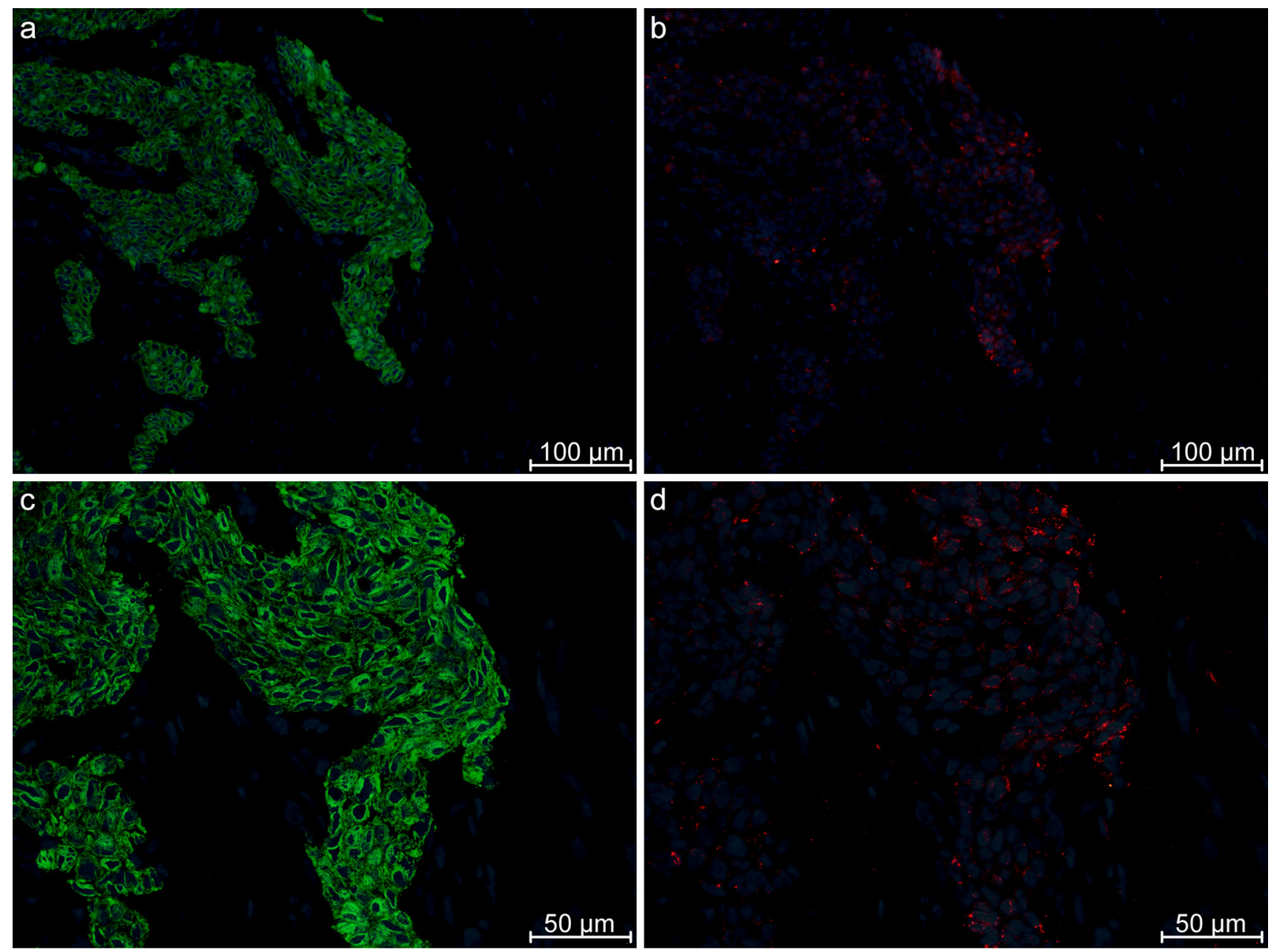

Fig. 4 Immunohistochemistry performed on cryostat tissue from a luminal breast cancer of patient 761. All pictures are merged with DAPI staining. The pictures a and $\mathbf{c}$ show staining against CK19. Picture b shows staining with $\mathrm{LH} \mathrm{7,} \mathrm{which} \mathrm{only} \mathrm{binds} \mathrm{a} \mathrm{subset} \mathrm{of} \mathrm{the} \mathrm{cancer}$

cells. Picture $\mathbf{d}$ is the exact same area as in $\mathbf{b}$, but in higher magnification. Stainings performed on this biopsy showed a slightly higher frequency of binding to cancer cells, and the staining were generally less grouped compared with staining on the basal-like cancers

\section{Test of antibody specificity by immunohistochemistry}

IHC was performed on cryopreserved breast tissue from biopsies of four different cancer patients. All tissue sections were co-stained with anti-CK19. This helps to distinguish cancer cells with luminal characteristics from surrounding stroma. The majority of the tested soluble antibody fragments did not show any particular cancer-specific staining, but rather strong staining in the surrounding stroma. However, the antibody fragment LH 7 showed staining toward several minor cell clusters within certain tumor cell nests. This staining pattern could indicate that this particular antibody fragment is associated with certain breast cancer subpopulations. The staining pattern of this antibody fragment does not distinguish between basal-like and luminal cancers. It bound subsets of cancer cells in all of the different cancer biopsies

tested. Examples of staining performed on the same basal-like cancer biopsy (P757) as used in the selection are shown in Figs. 2 and 3. Figure 2 shows staining in lower magnification for a more representative view and includes the proliferation control ki67 and a negative control. Figure 3 shows staining in higher magnification on three different areas on the same tissue section (P757). An example of staining performed on a luminal cancer (P761) is shown in Fig. 4. IHC was also performed on breast tissue from three healthy donors, which did not show any binding with LH 7 (Sup. 1).

\section{Discussion}

This paper describes the selection of a domain antibody LH 7, which in repeated immunohistochemistry experiments only recognizes minute cell clusters within certain tumor 
cell nests. This staining pattern indicates that LH 7 may recognize a breast cancer subpopulation.

The principle of the presented approach relies on the selection of antibody fragments binding to a chosen minute area of breast cancer tissue of interest. This is made possible by the use of phage display and shadow stick. The shadow stick shields the phage particles binding to the target area from UV-C exposure which renders all nonprotected phage particles non-replicable in E.Coli. This approach yields a low output of clones from each selection, while generating a relatively high frequency of phage antibodies binding to unique or upregulated antigens.

Selections were performed on a basal-like breast cancer tissue section with a high-density cluster of $\mathrm{CD} 271^{+}$cells within a single cancer nest. These $\mathrm{CD} 271^{+}$cells may potentially be classified as breast cancer stem cells [20]. To preserve the structural presentation of antigens, the $\mathrm{CD} 271^{+}$target area was identified on a separate slide, and the selections performed on consecutive neighboring slides. As the CD271 ${ }^{+}$cells were targeted within the tumor cell nests on tissue, the screening of recombinant antibodies by phage ELISA was performed on $\mathrm{CD} 271^{+}$breast cancer cells, which were single cell cloned from the breast cancer cell line BT474. In the initial phage ELISA screening, 315 phage antibodies from the 13 selections were tested. As CD271 ${ }^{+}$status is common in the myoepithelial cells surrounding tumor cell nests in tissue, these cells were convenient for the purpose of identifying and discarding binders of common epitopes, including binders of the antigen CD271. Thirty-five phage antibodies from the initial screening showed higher absorbance than epsilon and were tested by titration assay on both $\mathrm{CD} 271^{+}$cancer cells and CD $271^{+}$myoepithelial cells. In this assay, it was not the intensity of the absorbance values, which was of interest, but rather the binding difference between the two cell types. These screening and titration assays aided the prioritization of the selected phage antibodies for further evaluation by IHC.

IHC was performed with 11 different soluble antibody fragments on sections from the same biopsy as selected upon to ensure testing on the same tumor microenvironment as they initially bound. Additionally, three other biopsies were used since breast cancer may vary greatly in tumor heterogeneity and phenotype. The IHC experiments were repeated with different batches of purified antibody fragments with similar results. The antibody fragment LH 7 consistently showed binding to subsets of cancer cells within the tumor cell nests in all of the four different cancer biopsies. Hence, this particular antibody fragment recognizes an antigen expressed by a breast cancer subpopulation. The staining performed on the luminal cancer biopsy from patient 761 (Fig. 4) generally showed a higher frequency of staining to the cancer cells, indicating that the subpopulation expressing the cognate antigen of LH 7 may exist in more frequent numbers in this particular biopsy. There were also noticeable differences in the staining pattern in regard to the staining density, both on the same section (Fig. 3) and on another breast cancer subtype (Fig. 4). In some areas, the staining was more clustered in groups of coherent cells (Fig. 3f), and in other areas, it was more scattered around individual cancer cells. Such differences are highly expected due to the heterogeneity of breast cancer.

Immunohistochemistry experiments show that one of the selected antibody fragments, LH 7, is apparently specific toward certain breast cancer subpopulations. Identification and characterization of breast cancer subpopulations may provide new insight and treatment strategies. Further studies identifying and characterizing the subpopulations recognized by LH 7 could be highly valuable for understanding intra-tumor heterogeneity in breast cancer and developing new strategies for diagnosis and treatment. Furthermore, the antibody in itself may possess prospects in the development of reagents for targeted therapy.

Acknowledgments We thank Benedikte Thuesen, Københavns Privathospital and the donors for providing any normal breast biopsy material and Vera Timmermans Wielenga, Pathology Department, Rigshospitalet, for confirming the normalcy of the tissue and providing any cancer tissue. This work was supported by Novo Nordisk Foundation, the Danish Council for Research and Innovation, the Danish Council for Independent Research Technology and Production Sciences and the Sino-Danish center.

Conflict of interest The authors declare that there are no conflicts of interest.

Open Access This article is distributed under the terms of the Creative Commons Attribution 4.0 International License (http://creativecommons.org/licenses/by/4.0/), which permits unrestricted use, distribution, and reproduction in any medium, provided you give appropriate credit to the original author(s) and the source, provide a link to the Creative Commons license, and indicate if changes were made.

\section{References}

1. Marusyk A, Polyak K. Tumor heterogeneity: causes and consequences. Biochim Biophys Acta. 2010;1805(1):105-17. doi:10. 1016/j.bbcan.2009.11.002.

2. Polyak K. Heterogeneity in breast cancer. J Clin Invest. 2011;121(10):3786-8. doi:10.1172/jci60534.

3. Perou CM, Sorlie T, Eisen MB, van de Rijn M, Jeffrey SS, Rees $\mathrm{CA}$, et al. Molecular portraits of human breast tumours. Nature. 2000;406(6797):747-52. doi:10.1038/35021093.

4. Sorlie T, Perou CM, Tibshirani R, Aas T, Geisler S, Johnsen H, et al. Gene expression patterns of breast carcinomas distinguish tumor subclasses with clinical implications. Proc Natl Acad Sci USA. 2001;98(19):10869-74. doi:10.1073/pnas.191367098.

5. Network CGA. Comprehensive molecular portraits of human breast tumours. Nature. 2012;490(7418):61-70. doi:10.1038/ nature 11412 . 
6. Hu Z, Fan C, Oh DS, Marron JS, He X, Qaqish BF, et al. The molecular portraits of breast tumors are conserved across microarray platforms. BMC Genom. 2006;7:96. doi:10.1186/14712164-7-96.

7. Benetkiewicz M, Piotrowski A, Diaz De Stahl T, Jankowski M, Bala D, Hoffman J, et al. Chromosome 22 array-CGH profiling of breast cancer delimited minimal common regions of genomic imbalances and revealed frequent intra-tumoral genetic heterogeneity. Int J Oncol. 2006;29(4):935-45.

8. Nowell PC. The clonal evolution of tumor cell populations. Science. 1976;194(4260):23-8.

9. Cifone MA, Fidler IJ. Increasing metastatic potential is associated with increasing genetic instability of clones isolated from murine neoplasms. Proc Natl Acad Sci USA. 1981;78(11):6949-52.

10. Bonnet D, Dick JE. Human acute myeloid leukemia is organized as a hierarchy that originates from a primitive hematopoietic cell. Nat Med. 1997;3(7):730-7.

11. Clarke MF, Dick JE, Dirks PB, Eaves CJ, Jamieson CH, Jones DL, et al. Cancer stem cells-perspectives on current status and future directions: AACR workshop on cancer stem cells. Cancer Res. 2006;66(19):9339-44. doi:10.1158/0008-5472.can-06-3126.

12. Barabe F, Kennedy JA, Hope KJ, Dick JE. Modeling the initiation and progression of human acute leukemia in mice. Science. 2007;316(5824):600-4. doi:10.1126/science.1139851.

13. Michor F, Polyak K. The origins and implications of intratumor heterogeneity. Cancer Prev Res (Phila). 2010;3(11):1361-4. doi:10.1158/1940-6207.capr-10-0234.

14. Park CC, Bissell MJ, Barcellos-Hoff MH. The influence of the microenvironment on the malignant phenotype. Mol Med Today. 2000;6(8):324-9.

15. Tlsty TD, Coussens LM. Tumor stroma and regulation of cancer development. Ann Rev Pathol. 2006;1:119-50. doi:10.1146/ annurev.pathol.1.110304.100224.

16. Egeblad M, Nakasone ES, Werb Z. Tumors as organs: complex tissues that interface with the entire organism. Dev Cell. 2010;18(6):884-901. doi:10.1016/j.devcel.2010.05.012.

17. Knowles HJ, Harris AL. Hypoxia and oxidative stress in breast cancer. Hypoxia and tumourigenesis. Breast Cancer Res. 2001;3(5):318-22.
18. Junttila MR, de Sauvage FJ. Influence of tumour micro-environment heterogeneity on therapeutic response. Nature. 2013;501(7467):346-54. doi:10.1038/nature12626.

19. Larsen SA, Meldgaard T, Lykkemark S, Mandrup OA, Kristensen P. Selection of cell-type specific antibodies on tissue-sections using phage display. J Cell Mol Med. 2014. doi:10.1111/jcmm. 12568.

20. Kim J, Villadsen R, Sorlie T, Fogh L, Gronlund SZ, Fridriksdottir $\mathrm{AJ}$, et al. Tumor initiating but differentiated luminal-like breast cancer cells are highly invasive in the absence of basal-like activity. Proc Natl Acad Sci USA. 2012;109(16):6124-9. doi:10. 1073/pnas.1203203109.

21. Ronnov-Jessen L, Petersen OW. Induction of alpha-smooth muscle actin by transforming growth factor-beta 1 in quiescent human breast gland fibroblasts. Implications for myofibroblast generation in breast neoplasia. Lab Invest. 1993;68(6):696-707.

22. Larsen SA, Meldgaard T, Fridriksdottir AJ, Lykkemark S, Poulsen PC, Overgaard LF, et al. Selection of breast cancer specific antibodies using phage display on tissue-sections. J Mol Cancer. 2015. Submitted.

23. Mandrup OA, Friis NA, Lykkemark S, Just J, Kristensen P. A novel heavy domain antibody library with functionally optimized complementarity determining regions. PLoS ONE. 2013;8(10):e76834. doi:10.1371/journal.pone.0076834.

24. Villadsen R, Fridriksdottir AJ, Ronnov-Jessen L, Gudjonsson T, Rank F, LaBarge MA, et al. Evidence for a stem cell hierarchy in the adult human breast. J Cell Biol. 2007;177(1):87-101. doi:10. 1083/jcb.200611114.

25. Jensen KB, Jensen ON, Ravn P, Clark BF, Kristensen P. Identification of keratinocyte-specific markers using phage display and mass spectrometry. Mol Cell Proteomics. 2003;2(2):61-9. doi:10. 1074/mcp.M200049-MCP200.

26. Sorensen MD, Gonzalez Dosal R, Jensen KB, Christensen B, Kolvraa S, Jensen UB, et al. Epsilon haemoglobin specific antibodies with applications in noninvasive prenatal diagnosis. J Biomed Biotechnol. 2009;2009:659219. doi:10.1155/2009/ 659219. 